\title{
Introducing a New Method for Ground Structure Estimation using Microtremor Array Observation Technique
}

\author{
Yi Ben Cheah $^{1 *}$ and Tze Liang Lau ${ }^{1}$ \\ ${ }^{1}$ School of Civil Engineering, Universiti Sains Malaysia, Engineering Campus, 14300 Nibong Tebal, \\ Penang, Malaysia
}

\begin{abstract}
Ground structure characteristic is an important parameter in seismic site effect evaluation for earthquake structural design. Many geophysical methods can be used to estimate ground structure. The best field measurement option that requires least field effort and yet producing accurate estimation is the main concern of this study. This study applies microtremor array observation method to investigate the accuracy of dispersion curve estimated using Centerless Circular Array (CCA) methods of $5 \mathrm{~m}$ radius. The dispersion curve observed was assessed by comparing to theoretical dispersion curve generated from proposed shear wave velocity $\left(V_{s}\right)$ profile of sites. The observed dispersion curve shows good agreement with theoretical dispersion curve over a wide frequency range, which is ranging from $3-10 \mathrm{~Hz}$. This segment of dispersion curve can be utilized to estimate ground structure by means of inversion of dispersion curve. CCA method is capable to be used to estimate ground structure in term of Vs profile.
\end{abstract}

\section{Introduction}

Local site effect is one of the main concerns in earthquake design of structures as the natures of the arriving seismic waves can be modified by local geological condition. Depending on local near-surface ground condition, the shaking intensity and amplitude of ground motion can be amplified due to reflection and refraction of seismic waves at the boundary between bedrock formation and soft sediment deposits.

Shear wave velocity profile of soil structure is the key parameter in evaluating local site effect. Generally, the shear wave velocity profile at site is determined by using conventional geophysical methods, such as downhole, crosshole, suspension logging or multichannel analysis of surface wave. Time and manpower required to conduct these tests are high due to the reason that these methods involve either boring of holes or application of active seismic sources. Besides, these methods present practical difficulties in cases where the sites are located within urban area because they involve ground boring, which is a destructive action to urban area as most spaces are already paved or occupied. In the case

\footnotetext{
* Corresponding author: benjamincheah1994@gmail.com
} 
where artificial seismic source is needed in these conventional methods, the impact noise due to artificial seismic source will also cause disturbance to the surrounding occupants.

The mentioned difficulties can be overcome by using microtremor measurement. In microtremor measurement, the ambient ground motion is recorded by microtremor sensors deployed on the ground without performing boring of holes or application of seismic sources. Microtremor measurement has been conducted by many researchers to estimate ground structure over the decades [1-12].

This paper presents application of Centerless Circular Array (CCA) method in analysing the microtremor array data to obtain dispersion curve of surface waves. CCA method is a new analysis method developed by Cho et al. [13] based on Spatial Autocorrelation (SPAC) Method in recent years. Acquiring the accurate estimation of ground structure using the smallest array in microtremor observation is the upmost priority in field measurement. SPAC method requires a larger array and more number of sensors to give a more accurate result [14]. However, larger array size and more sensors will result in higher field effort and lower survey efficiency. CCA method only requires minimum of three sensors to give similar dispersion curve estimation and it has advantage in analysing data recorded using a smaller array size [13].

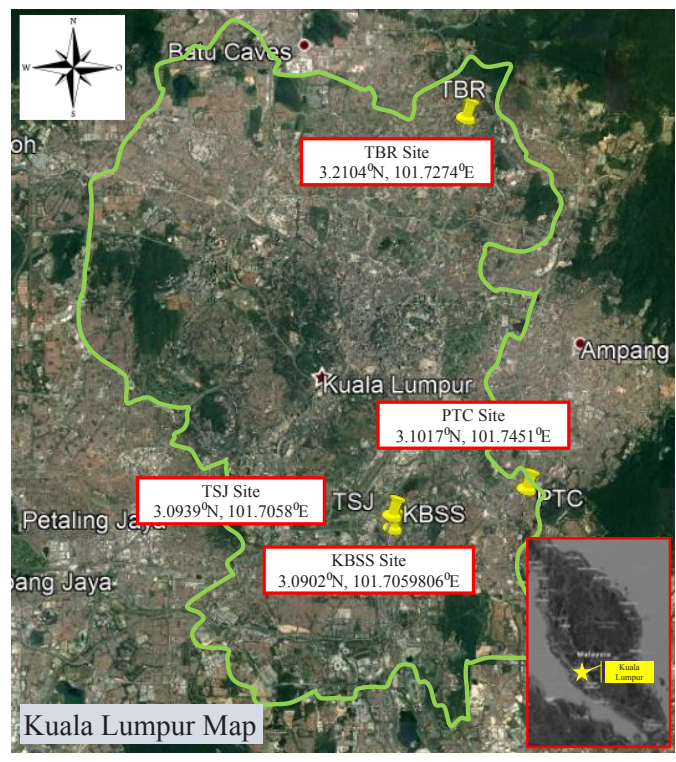

Fig. 1. Locations of microtremor measurement in Kuala Lumpur.

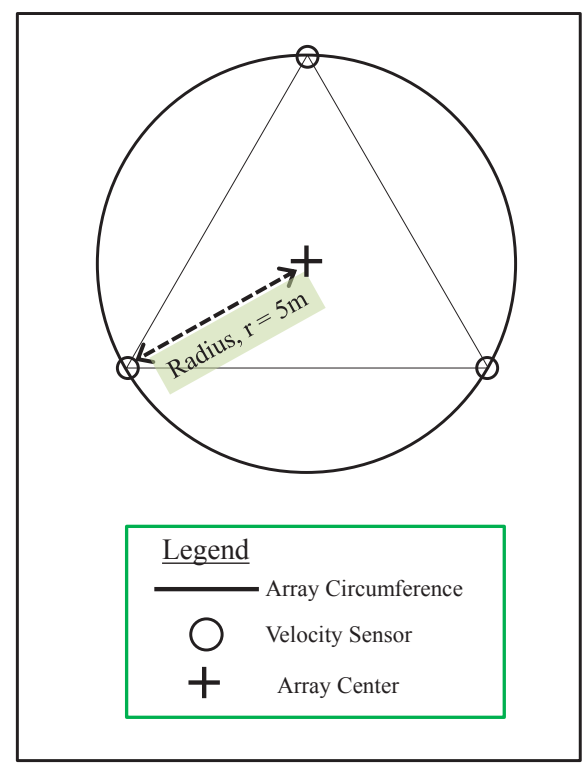

Fig. 2. Microtremor array arrangement for array radius of $5 \mathrm{~m}$.

Table 1. Specification of the velocity sensor.

\begin{tabular}{|l|l|}
\hline Dimension & $104(\mathrm{~W}) \times 104(\mathrm{H}) \times 104(\mathrm{D}) \mathrm{mm}$ (Adjustable height) \\
\hline Weight & About $1.5 \mathrm{~kg}$ \\
\hline Sensor Type & Moveable Coil \\
\hline Measuring Composition & 3 components $(\mathrm{X}, \mathrm{Y}, \mathrm{Z})$ \\
\hline Predominant Frequency & $1.9 \mathrm{~Hz}$ to $2.1 \mathrm{~Hz}$ \\
\hline Sensitivity & Above $0.8 \mathrm{~V} / \mathrm{kine}$ \\
\hline Damping Ratio & 0.7 (When connected to an external $100 \mathrm{~kW}$ wiring) \\
\hline Shunt Impedance & Built-in \\
\hline Environmental Condition & $-20^{\circ} \mathrm{C}$ to $+55^{\circ} \mathrm{C}$ \\
\hline Amplitude Measurement Range & $\pm 2 \mathrm{~mm}$ (Range of movement $5.4 \mathrm{mmpp})$ \\
\hline
\end{tabular}




\begin{tabular}{|l|l|}
\hline Moveable Mass & $29 \mathrm{~g}$ to $40 \mathrm{~g}$ \\
\hline Coil Resistance & $7000 \mathrm{~W}$ to $7700 \mathrm{~W}$ \\
\hline
\end{tabular}

\section{Microtremor field measurement}

Microtremor field measurement was conducted at four sites located in Kuala Lumpur, namely TBR, PTC, TSJ and KBSS, where the actual soil profiles near the sites were known based on existing borelog data. The measured sites are as shown in Figure 1. In order to improve the quality of data, these sites were selected based on some criteria such as least human activities, away from traffic, flat terrain and accessible as stated in guidelines for ambient vibration measurement in SESAME project [15]. The array arrangement consisted of circular array formed by three numbers of three-component velocity sensors along the circumference of the circle with $5 \mathrm{~m}$ radius and the sensors were spaced at equal-distant. The formation of the array measurement is as shown in Figure 2. The field measurement duration is 25 minutes. The specification of velocity sensor is tabulated in Table 1 .

\section{Data processing and analysis}

The observed field data was analysed using BIDO 2.0 application based on CCA method. The application split the data into $10.24 \mathrm{sec}$ segments and segments that are contaminated by noises were discarded. CCA method was developed by [13]. They uses a spectral representation which may be considered a general case to SPAC method. The vertical component of microtremor records are used to determine the phase velocities of Rayleigh waves from sensors located on a circle without using a sensor at the center. The CCA coefficient is defined in Equation 1, where $r$ is inter-station distance. $\omega$ and $k$ are angular frequency and wavenumber respectively. $J_{0}$ and $J_{l}$ are zero and first order Bessel functions. $G_{0}$ and $G_{l}$ are power spectral densities.

$$
\frac{G_{0}(\omega, r)}{G_{l}(\omega, r)}=\frac{J_{0}^{2}\left[r k_{l}(\omega)\right]}{J_{l}^{2}\left[r k_{l}(\omega)\right]}
$$

The wavenumber, $k(\omega)$ is estimated by fitting to $\left[J_{0}(k r) / J_{l}(k r)\right]^{2}$ with the measured CCA coefficient at each inter-station distance for each frequency. The phase velocity of surface wave is calculated based on Equation 2,

$$
c(\omega)=\frac{\omega}{k(\omega)}
$$

where $c(\omega)$ is phase velocity of surface wave.

\section{Results and discussion}

The fieldwork data was analysed to obtain observed dispersion curve by using CCA method. The observed dispersion curve is deemed to be accurate if the observed dispersion curve shows similar trend with the theoretical dispersion curve. The theoretical dispersion curve was developed based on the proposed soil profile obtained from borelog. The input parameters for theoretical dispersion curve generation in the program are shear wave velocity $\left(\mathrm{V}_{\mathrm{S}}\right)$, compression wave velocity $\left(\mathrm{V}_{\mathrm{P}}\right)$, density and thickness of the respective soil layers. The phase velocity and frequency were then calculated based on Newton's method. 
The equivalent shear wave velocity $\left(\mathrm{V}_{\mathrm{S}}\right)$ profile and number of blows of standard penetration test $\left(\mathrm{N}_{\mathrm{SPT}}\right)$ profile for four sites is shown in Figure 3. The $\mathrm{V}_{\mathrm{S}}$ profile for each site consists of three layers, which are $0-180 \mathrm{~m} / \mathrm{s}, 180$ to $360 \mathrm{~m} / \mathrm{s}$ and 360 to $800 \mathrm{~m} / \mathrm{s}$. The $\mathrm{V}_{\mathrm{S}}$ range with its corresponding $\mathrm{N}_{\mathrm{SPT}}$ range for each layer is defined based on Table 3.1 in Eurocode 8 [16] as simplified in Table 2. Theoretical and observed dispersion curves were plotted in the same graph to evaluate the accuracy of observed dispersion curve by means of comparison as shown in Figure 4.

Table 2. VS range and its corresponding NSPT range.

\begin{tabular}{|c|c|c|}
\hline \multirow{2}{*}{ Layer } & \multicolumn{2}{|c|}{ Parameters } \\
\cline { 2 - 3 } & $\mathrm{V}_{\mathrm{S}}(\mathrm{m} / \mathrm{s})$ & $N_{S P T}($ blows $/ 30 \mathrm{~cm})$ \\
\hline 3 & $<180$ & $<15$ \\
\hline 2 & $180-360$ & $15-50$ \\
\hline 1 & $360-800$ & $>50$ \\
\hline
\end{tabular}

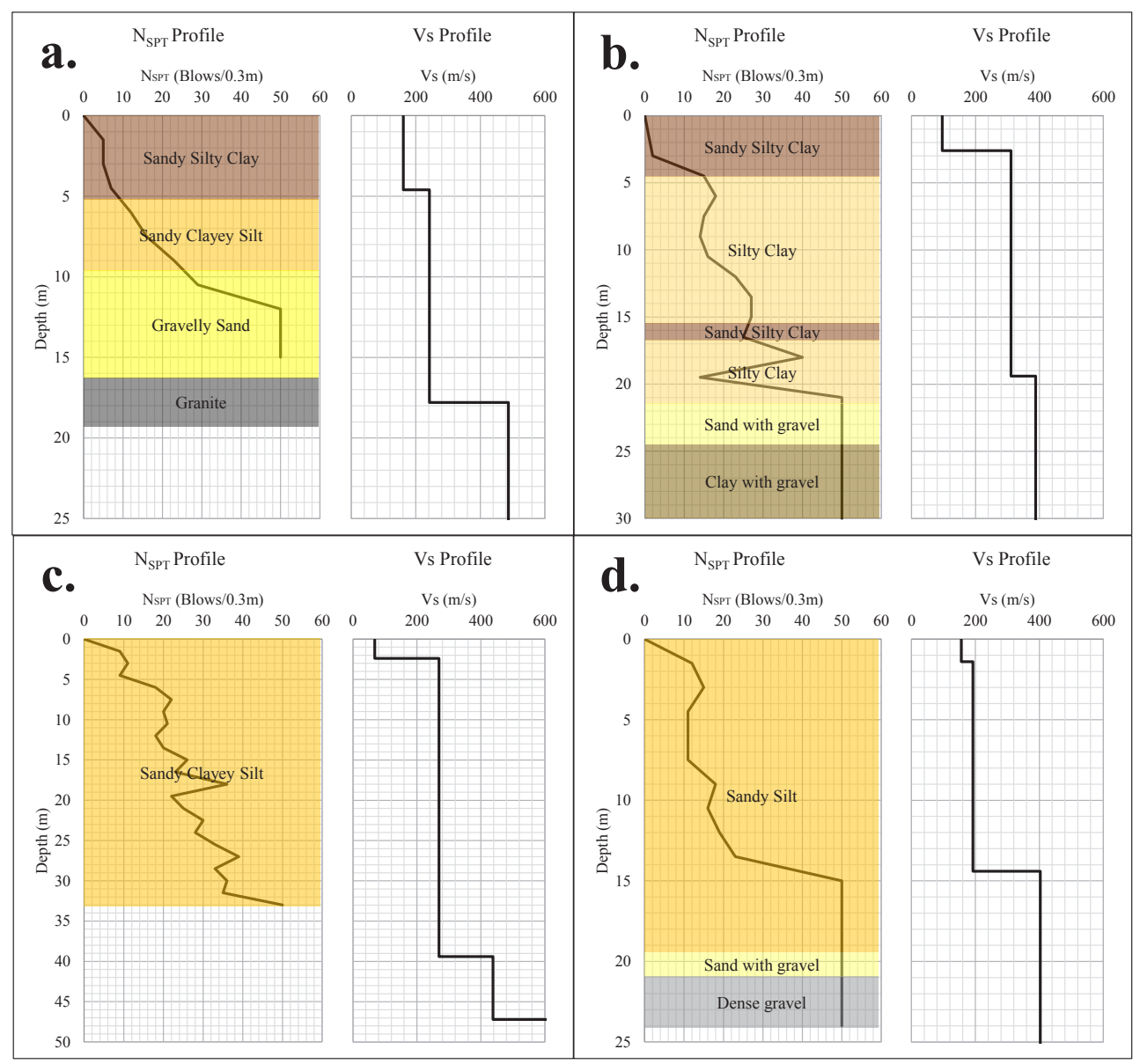

Fig. 3. $\mathrm{N}_{S P T}$ and $\mathrm{V}_{S}$ profile of each site. (a. TSJ site; b. TBR site; c. PTC site; d. KBSS site)

Based on Figure 4, the observed dispersion curves for TSJ, PTC and KBSS sites shows a very good agreement to theoretical dispersion curve for higher frequency range, which is from $3-10 \mathrm{~Hz}$ for TSJ and PTC sites, and from $4-10 \mathrm{~Hz}$ for KBSS sites. Although the observed dispersion curve for TBR sites shows slight fluctuation in high frequency range, 
but it shows a similar trend with theoretical dispersion curve from $3-10 \mathrm{~Hz}$ frequency range.
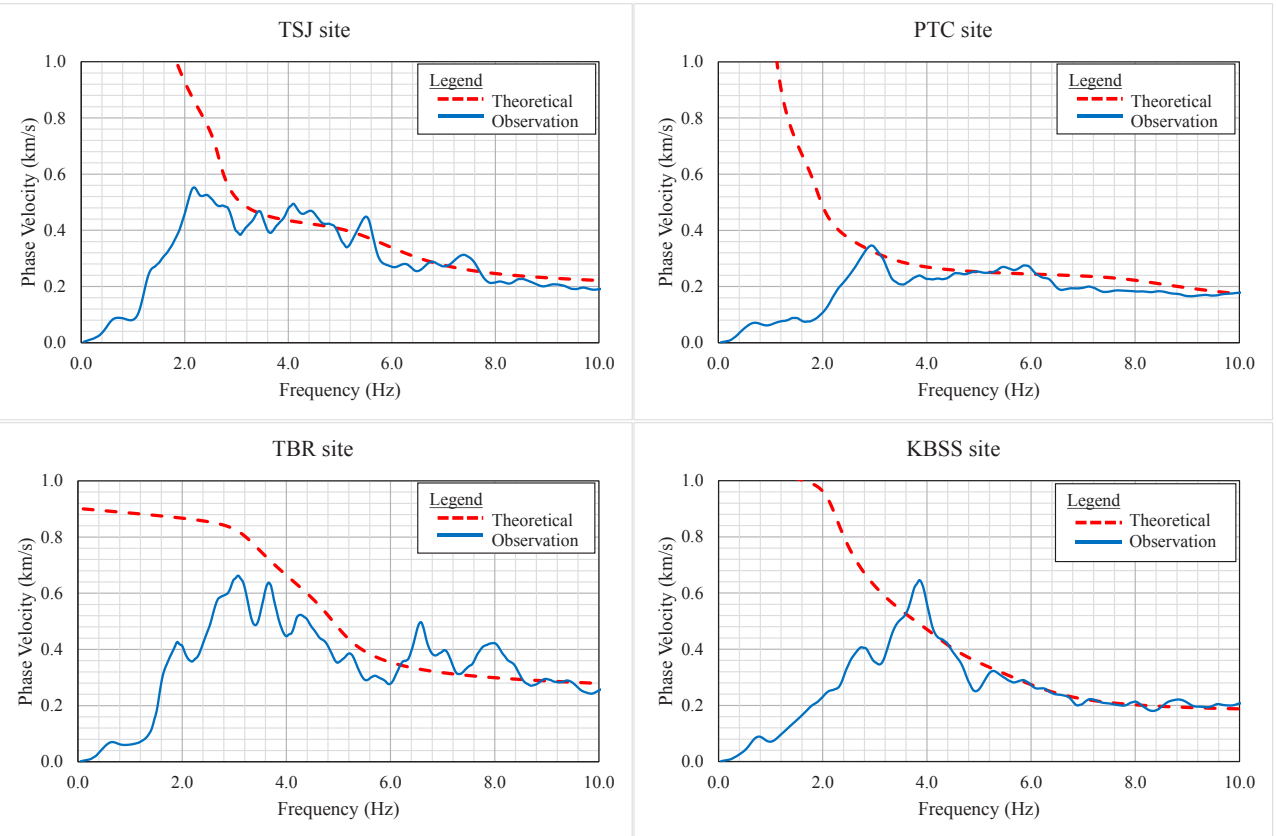

Fig. 4. Observed dispersion curve of each site.

\section{Conclusions}

Microtremor array observation with $5 \mathrm{~m}$ radius were conducted at four sites in Kuala Lumpur, which are TSJ, PTC, KBSS and TBR sites. The observed dispersion curve for four sites show good agreement with theoretical dispersion curve over a wide frequency range, which is from 3 to $10 \mathrm{~Hz}$. Thus, dispersion curve obtained using CCA method from small array is capable to estimate the ground structure of site in term of Vs profile.

The authors would like to express their sincere gratitude to Ministry of Higher Education (Malaysia) for funding this research through Exploratory Research Grant Scheme (ERGS) Grant No. 203/PAWAM/6730114. Special appreciation also goes to Gui Win Way and Tan Chin Guan for assisting in conducting field work measurement and analysing the data.

\section{References}

1. T. Satoh, H. Kawase, S.i. Matsushima, Bull. Seismol. Soc. Am., 91, 206-218 (2001)

2. M.W. Asten, T. Dhu, Proceedings of Australian Earthquake Engineering Society Conference, 8 (2002)

3. H.F. Estrella, J.A. González, Geophys. Intl., 42, 227-236 (2003)

4. M.W. Asten, T. Dhu, N. Lam, Proceedings of the 13th World Conference on Earthquake Engineering, 16, Paper No. 2903 (2004) 
5. R. Maresca, L. Nardone, D. Galluzzo, M. La Rocca, E. Del Pezzo, Proceedings of the Third International Symposium on the Effects of Surface Geology on Seismic Motion, Paper No. 073 (2006)

6. M. Davoodi, E. Haghshenas, M. Esfahanizadeh, M. Mirjalili, S. Atashband, Proceedings of 14th World Conference on Earthquake Engineering, Paper No. 020161 (2008)

7. H. Morikawa, M. Komazawa, H. Chen, C. Takahashi, T. Shosaka, H. Kawatsure, Proceedings of the 14th World Conference on Earthquake Engineering, Paper No. 020034 (2009)

8. J. Kiyono, Y. Ono, A. Sato, T. Noguchi, R.R. Putra, ASEAN Eng. J., 1, 66-81 (2011)

9. H.E. Zaineh, H. Yamanaka, R. Dakkak, A. Khalil, M. Daoud, Soil Dyn. Earthq. Eng., 39, 88-99 (2012)

10. S. Hamasaki, T.L. Lau, H. Morikawa, Y. Ogura, J. Jpn. Soc. Civil Eng., 69 (2013)

11. L.J. Su, X.Q. Xu, H.J. Liao, X.Y. Geng, Proceedings of IOP Conference Series: Earth and Environmental Science, 26, 012026 (2015)

12. B. Setiawan, M. Jaksa, M. Griffith, D. Love, Analysis of microtremor array measurement using the spatial autocorrelation (SPAC) method across the Adelaide City (The University of Adelaide, Adelaide City, 2016)

13. I. Cho, T. Tada, Y. Shinozaki, Geophysics, 69, 1535-1551 (2004)

14. H. Okada, The microtremor survey method (American Geophysical Union, Washington, 2003)

15. SESAME, Guidelines for the Implementation of the H/V Spectral Ratio Technique on Ambient Vibrations Measurement, Processing and Interpretation (SESAME European Research Project, 2004)

16. EN 1998-1:2004: Design of structures for earthquake resistance: Part 1: General rules, seismic actions and rules for buildings (European Committee for Standardization, 2004) 